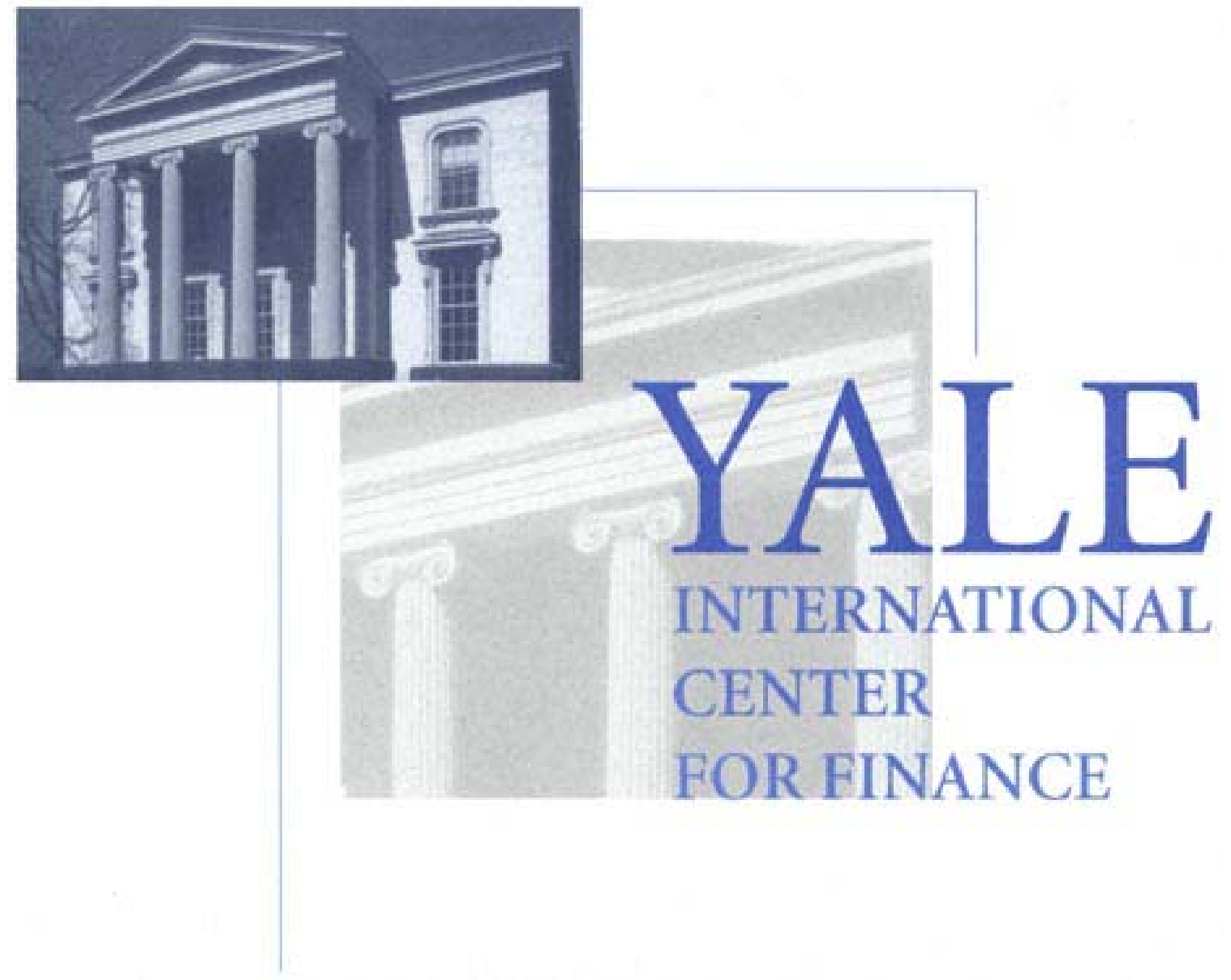

Yale ICF Working Paper No. 00-17

May 2003

\title{
Double Auction Dynamics: Structural Effects Of Non-Binding Price Controls
}

\author{
Dhanajay K. Gode \\ New York University \\ Shyam Sunder \\ Yale School of Management
}

This paper can be downloaded without charge from the Social Science Research Network Electronic Paper Collection: http://ssrn.com/abstract_id=219068 


\title{
Double Auction Dynamics: Structural Effects of Non-Binding Price Controls
}

\author{
Dhananjay (Dan) K. Gode \\ Stern School of Business \\ New York University \\ 427 Tisch Hall, 40 West 4th Street \\ New York, NY 10012 \\ dgode@stern.nyu.edu \\ http://www.dangode.com \\ Shyam Sunder \\ Yale School of Management \\ PO Box 208200, 135 Prospect Street \\ New Haven, CT 06520-8200 \\ shyam.sunder@yale.edu \\ http://www.som.yale.edu/faculty/sunder
}

Revised Draft, May 2003

(C) Copyright. All rights reserved.

We are grateful for comments received at workshops at California Institute of Technology, Carnegie Mellon University, Econometric Society, Economic Science Association, European University Institute, Renmin University, University of Amsterdam, University of Bonn, Universitat Pompeu Fabra, and Yale University. We would also like to thank the two anonymous referees and the editor for their numerous suggestions to improve the paper. The paper can be downloaded from http://papers.ssrn.com/sol3/papers.cfm?abstract id=219068 or the authors' web sites. 


\title{
Double Auction Dynamics: Structural Effects of Non-Binding Price Controls Dhananjay (Dan) K. Gode and Shyam Sunder
}

\begin{abstract}
In competitive equilibrium, non-binding price controls (that is, price floors below and ceilings above the equilibrium) should not affect market outcomes, but in laboratory experiments they do. We build a simple dynamic model of double auction markets with "zero-intelligence" (ZI) computer traders that accounts for many, though not all, of the discrepancies between the data and the Walrasian tatonnement predictions. The success of the model in organizing the data, and in isolating various consequences of price controls, shows that the simple ZI model is a powerful tool to gain insights into the dynamics of market institutions.
\end{abstract}

JEL Classifications: D44, D61

Keywords: Price Controls, Zero-Intelligence, Double Auction Dynamics, Allocative Efficiency

Gode and Sunder, Double Auction Dynamics, 5/30/03 


\section{Double Auction Dynamics: Structural Effects of Non-Binding Price Controls}

In an astonishing variety of contexts, apparently complex structures or behaviors emerge from systems characterized by very simple rules.

Murray Gell-Mann (The Quark and the Jaguar p. 99-100)

\section{Introduction}

With utility-maximizing traders, price floors below or ceilings above the equilibrium price should not affect competitive equilibrium, but they do in laboratory auctions [Isaac and Plott (1981), Smith and Williams (1981), and Coursey and Smith (1983)]. We use a "zero-intelligence" (ZI) model of traders, who bid and ask randomly but avoid losses, have no memory, and ignore market rules, to explain salient aspects of this data. Our analysis highlights how price limits alter the statistical properties of interaction among traders.

The ZI model has three appealing features. First, it shows that market rules can affect aggregate market outcomes even if individuals ignore these rules [see Becker (1962) and Gode and Sunder (1993a, 1993b, and 1997)]. Second, the ZI model explains why many important experimental outcomes are robust to variations in subject backgrounds by showing how market rules largely determine the statistical properties of interactions among traders in these settings. Third, the simplicity of ZI traders enables us to comprehend these interactions. The analysis of markets in which a small number of traders act sequentially is otherwise intractable even with naïve traders who have any memory, let alone strategic traders.

Overall, the ZI traders are a tool to isolate and understand the effect of market rules on market outcomes. Understanding the effects of market rules and other social institutions is crucial because rules are observable and controllable, while individual strategies are inherently private and not directly controllable. Theories based on the effect of market rules are therefore easier to test. The ZI model provides a benchmark of the "structural" effect of market rules. The traditional strategic 
model in which traders respond fully to changes in market rules is another benchmark. The two benchmarks bracket the range in which human behavior lies.

The paper makes two major contributions. First, the paper shows that many important effects of price controls persist when human traders are replaced by ZI traders. Second, the paper highlights the role of extramarginal traders and shows how non-binding price controls affect market outcomes by limiting or facilitating the entry of extramarginal traders. ${ }^{1}$ By ignoring the impact of non-binding controls on the participation of extramarginal traders during the process of convergence to equilibrium, competitive equilibrium theory misses out on the impact of non-binding price controls on market outcomes.

The paper brings out two effects of price controls on the likelihood of entry of extramarginal traders into a market. The first effect increases the likelihood of entry by extramarginal traders while the second effect decreases the likelihood of entry by extramarginal traders. Consider a non-binding price ceiling. By placing an upper limit on bids, a price ceiling inhibits the ability of intramarginal buyers to outbid extramarginal buyers, thereby increasing the likelihood of the participation by extramarginal buyers, and lowering the allocative efficiency. ${ }^{2}$ On the other hand, a price ceiling drives out the extramarginal sellers whose costs exceed the ceiling. Such exclusion boosts the allocative efficiency initially, but also precludes efficiency recovering trades between intramarginal buyers and extramarginal sellers in case extramarginal buyers initially displace intramarginal buyers. The initial exclusion of extramarginal sellers therefore raises efficiency while their absence in later rounds lowers efficiency.

\footnotetext{
${ }^{1}$ Extramarginal traders have units that are not traded in competitive equilibrium, i.e., the units to the right of the intersection of demand and supply. Units to the left are intramarginal units.

${ }^{2}$ Allocative efficiency is the ratio of the actual to the potential gains from trade (the sum of the consumer and producer surplus). It may fall short of 100 percent if traders fail to conclude feasible trades or extramarginal traders enter into trades and do not eventually retrade with intramarginal traders. Market frictions, such as asymmetric information and trading costs, often limit retrading [see Gode and Sunder (1997)].
} 
Section 2 presents prior experimental findings, Section 3 presents the ZI model, Section 4 presents our simulation results, Section 5 analyzes and explains the simulation results, and Section 6 summarizes and concludes the paper.

\section{Prior Research}

Price controls, such as minimum wage laws and agricultural price maintenance, are an important and common form of market regulation. The Walrasian tatonnement model predicts that in competitive equilibrium (CE) non-binding price controls should not affect transaction prices and quantity traded. ${ }^{3}$ In contrast, Scherer (1970, p. 352) predicts that non-binding price ceilings will serve as a "focal point" for collusion among sellers to keep the prices near the ceiling, i.e., above the CE price. Field data cannot resolve such conflicting predictions because the demand and supply are rarely observable with sufficient precision.

The laboratory experiments of Isaac and Plott (1981), Smith and Williams (1981), and Coursey and Smith (1983) reject the focal point hypothesis. Figures 1 and 2 show the representative results reproduced from Figures 1 and 3 respectively from Smith and Williams, 1981. The three panels of Figure 1 show the demand and supply functions, equilibrium price (horizontal dashed lines), and transaction price paths (dots) for three markets of four periods each. In the first market, there is a price floor five points below the equilibrium price; in the second market, there is a price ceiling five points above the equilibrium price; and in the third market, there are no price controls. The upper panel of Figure 2 corresponds to the middle panel of Figure 1 for a market with price ceiling at five points above the equilibrium price of 645 . The left-hand side of Figure 2 shows the frequency polygon of offers (dashed line with hollow circle markers) and bids (continuous line with dark circle

\footnotetext{
${ }^{3}$ A floor is the lower limit and a ceiling is the upper limit on bids, asks, and transaction prices. As the analysis of price ceilings and floors is symmetrical, this paper refers only to price ceilings. Non-binding ceilings are ceilings above the competitive equilibrium (CE) price.
} 
markers), while the right-hand side shows the frequency polygon of transaction prices. The bottom panel of Figure 2 corresponds to the bottom panel of Figure 1 for a market without price controls.

These experiments show that once human markets converge to competitive equilibrium (typically after repeated trading under the same demand and supply), non-binding price ceilings have no effect. However, ceilings do have the following effects on convergence to equilibrium: (1) Transaction prices are initially skewed away from the ceiling and the skew diminishes as the ceiling is raised (the "buffer effect"). (2) Intraperiod transaction price series has a positive slope. (3) The variability of transaction prices declines for later transactions within a period. (4) Allocative efficiency remains close to 100 percent, i.e., non-binding ceilings affect total realized profits only marginally. (5) The lowering of transaction prices transfers some profits from sellers to buyers. (6) The difference in the bargaining ability of buyers and sellers persists if it was present before the imposition of ceiling. (7) There is transient overshooting of transaction prices above the price ceiling after the ceiling is removed.

Isaac and Plott (1981) and Smith and Williams (1981) conjecture that non-binding ceilings depress transaction prices by forcing sellers to lower their initial asks to, or below, the ceiling, and which induces buyers to lower their initial bids. Isaac and Plott (1981) further conjecture that removing non-binding ceilings affects prices by making additional strategies available to the traders, or because a mere announcement of a change perturbs experimental markets. It is difficult to use mathematical or computer models of human behavior ${ }^{4}$ to verify these conjectures about the initial

\footnotetext{
${ }^{4}$ Writing programs to mimic traders is complex [Rust, Palmer, and Miller (1993)]. Because cognitive psychology provides conjectures that specify only a few aspects of behavior, writing a workable computer program requires one to choose from a large set of ad-hoc assumptions about human behavior. That is, there is no consensus yet as to how to mimic economic behavior via programs. Even if such a consensus existed, the complexity of these programs would perhaps make it difficult to understand how behavior interacts with market rules to influence market outcomes.
} 
phases of trading in which traders are learning about market conditions. Therefore, instead of trying to mimic human behavior, we use the simple ZI model to isolate the structural effects of price limits.

\section{Model}

We now describe the trader behavior, market rules, and demand and supply.

\subsection{Zl Trader Behavior}

Consider a market consisting of $\mathrm{N}$ buyers and $\mathrm{N}$ sellers. Each buyer has the right to buy some units and each seller has the right to sell some units. Let $v_{i j}$ denote the value of the $i^{\text {th }}$ buyer's $j^{\text {th }}$ unit and $\mathrm{c}_{\mathrm{ij}}$ denote the cost of the $\mathrm{i}^{\text {th }}$ seller's $\mathrm{j}^{\text {th }}$ unit. The costs and values are private information. The values sorted in a descending order constitute the market demand while the costs sorted in an ascending order constitute the market supply.

ZI traders avoid losses. When bidding for its $\mathrm{j}^{\text {th }}$ unit, the $\mathrm{i}^{\text {th }}$ buyer's bids are independently and uniformly distributed between 0 and $\mathrm{v}_{\mathrm{ij}}$ (the unit's value to the buyer). When asking for its $\mathrm{j}^{\text {th }}$ unit, the $\mathrm{i}^{\text {th }}$ seller's asks are independently and uniformly distributed between $\mathrm{c}_{\mathrm{ij}}$ (unit's cost to the seller) and an upper bound $\mathrm{M}$, which is set exogenously by market rules. ${ }^{5}$ In our simulations, as described next, ZI traders do not respond to other bids, asks, prior transactions, and price ceilings.

\subsection{Market Rules}

Each market was run for 100 periods on a single computer as a continuous double auction without replacement (see the Appendix for details). Two aspects of market rules are discussed in the following subsections.

\footnotetext{
${ }^{5}$ We set $\mathrm{M}=93$ (see Tables 1, 2 and 3) to make the demand and supply symmetric. Raising M shifts the prices slightly upward, and vice versa with a negligible effect on the allocative efficiency.
} 


\section{No retrading and allocative efficiency}

Buyers could bid multiple times for a trade and sellers could ask multiple times for a trade until the bids exceeded the ask, but retrading was not allowed. That is, the buyers could not resell the units they had bought earlier and the sellers could not sell short and cover up later. Thus, a trader could either buy or sell, but not do both.

We did not allow retrading because of two reasons. First, experimental auctions and their gametheoretic models of commodity markets often disallow retrading because it is frequently not feasible in markets for services, perishable products, and products that have asymmetric information or high transactions costs. Retrading is, of course, permitted in asset markets, which we do not examine. Second, retrading makes allocative efficiency a moot issue because given sufficient time retrading ensures $100 \%$ allocative efficiency.

Allocative efficiency is the ratio of actual total profits to the maximum possible total profits. Allocative efficiency can be less than $100 \%$ if traders leave money on the table by refusing to conclude profitable trades, or if extramarginal traders displace intramarginal traders. Since, given sufficient time, ZI buyers and sellers always conclude all profitable trades, the first source of inefficiency cannot exist in our markets.

The second source of inefficiency, which is due to the displacement of intramarginal traders by extramarginal traders, gets to the core of the allocative role of markets. Consider for example a market with one seller S1 who can produce a unit at a cost of $\$ 7$ and two buyers B1 and B2 who value a good at $\$ 19$ and $\$ 13$ respectively. Allocative efficiency would be $100 \%$ if $\mathrm{S} 1$ sold to B1 while B2 is left out of the market. This reflects the most efficient allocation because B1 values the good more than S1. Allocative efficiency would, however, be only 50\% if S1 sold to B2 and B1 is left out of the market. (The total realized profits would be $\$ 13-\$ 7=\$ 6$, while the maximum possible 
profits are $\$ 19-\$ 7=\$ 12$.) If we allowed retrading, then buyer B2 would eventually resell to buyer B1, making the allocative efficiency $100 \%$. With multiple sellers, such retrading would make the allocative efficiency $100 \%$ if the extramarginal sellers sold short and covered up their short sales by buying from intramarginal sellers. As previously mentioned, we do not allow such retrading in order to understand how rules affect allocations in real world markets that often limit retrading.

\section{Duality of rules and behavior}

There are two perspectives on how one can implement market rules. For example, one can say that sellers choose the highest bid (behavioral perspective) or that market rules give priority to the highest bid (institutional perspective). Similarly, instead of the market rejecting bids and asks above the ceiling, one can say that traders submit only valid bids and asks. Many market outcomes therefore have dual interpretations. In real markets, it is difficult to identify which phenomena are purely due to market rules if traders change their behavior in response to market rules.

ZI simulations allow us to isolate the impact of market rules on market outcomes because we fix ZI behavior and change market rules. We implement price controls in two modes. In the reject mode, bids and asks above the ceiling are rejected. ${ }^{6}$ In the reset mode, bids above the ceiling are reset to the ceiling instead of being rejected because a buyer would not object to a lower bid, but asks above the ceiling are rejected because a seller may object to a lower ask. In other words, bid $=$ minimum (bid, ceiling), which creates a point mass of probability of bids at the ceiling.

\footnotetext{
${ }^{6}$ The invalid bids and asks in the reject mode are simply rejected and the buyers and sellers must wait for their next turn to submit another bid or ask. The buyers and sellers are not asked to keep submitting another bid or ask until they submit a valid bid or ask. In other words, buyers and sellers are not asked to change the support of the distribution of their bids and asks so that they submit only valid, loss-avoiding bids and asks. Changing the support of the distribution is akin to modifying the demand and supply. For example, the demand curve above a ceiling is reset to the ceiling and the supply curve above the ceiling is truncated. Although the results of such simulations would be quantitatively different from either the reject or reset modes, the insights obtained from these two modes should extend to other conceivable modes.
} 


\subsection{Demand and supply}

The first set of simulations used the demand and supply shown in Table 1, which is the same as Smith and Williams' (1981) Table 1. Each trader has five or six units but can trade only one unit at a time. To maximize a trader's profits, Smith and Williams assume that a buyer trades his units in the descending order of their values, and a seller sells his units in the ascending order of their costs. The competitive equilibrium price is 46.5 and the quantity is 12 units.

The second set of simulations used the same aggregate demand and supply (Table 2) but each trader was assigned only one unit with a compensating increase in the number of traders. We used this variation because when each trader has multiple units but can trade only one unit at a time, the bids and asks at any instant depend only on the highest valued unit remaining with each buyer and the lowest cost unit remaining with each seller. Thus, very few, if any, extramarginal units are "in the market" at the beginning of a period and the chance for extramarginal units to displace the intramarginal units in trading is small. When each trader can trade only one unit, all untraded units affect market outcomes, as they would in reality.

Finally, to increase the chances of finding efficiency effects of price controls, we used the demand-supply schedule in Table 3, where the lower bound of efficiency, which occurs when all possible units (intramarginal as well as extramarginal) are traded, is only 56 percent. In Smith and Williams' demand and supply, there are only six extramarginal units, all relatively close to the margin and the lower bound of efficiency is 88 percent. 


\section{ZI Simulations with Smith and Williams Demand and Supply}

The ZI results in Sections 4.1 to 4.5 replicate the first five effects of non-binding price controls listed in Section 2. ${ }^{7}$ The existence of these effects with ZI traders who ignore market rules shows that market rules, even if they do not directly affect behavior, affect market outcomes by restricting the feasible set of bids, asks, and trades; and produce market outcomes that are usually attributed to changes in behavior. We defer the explanation of ZI outcomes until Section 5.

\subsection{Price Distribution}

Panel 1 of figure 4 and column 1 of Table 4 show the benchmark with no ceiling. The mean price is 46.5 , which equals the CE price. The price distribution is symmetric. Panel 2 of Figure 4 and Column 2 of Table 4 show the effect of rejecting bids and asks above the ceiling. The mode of transaction prices is between the ceiling of 47 and equilibrium price of 46.5 , and the distribution is skewed away from the ceiling. The mean price has a statistically significant $(\alpha=.000)$ drop from 46.5 (with no price control) to 45.01 (with price control), paralleling the human outcomes shown in Figures 2 and 3. Panel 3 of Figure 4 and Column 3 of Table 4 show the effect of resetting bids above the ceiling reset to the ceiling, but rejecting asks above the ceiling. (See the discussion of the "reset mode" in Section 3.3). The effect is similar to Panel 2 except that the mean price and the modal density at the price control are higher. Panel 4 of Figure 4 and Column 5 in Table 4 show the results from Smith and Williams' demand and supply functions in which each trader has only one unit to trade (see Table 2 and Section 3.1). Again, the effect of the price ceiling on transaction prices is similar to Panel 2 except that the mean price and the modal density at the price control are higher.

\footnotetext{
${ }^{7}$ We cannot replicate the effects of differences in bargaining ability (effect 6) because all ZI traders are identical. We also cannot replicate transient overshooting (effect 7) because ZI traders lack memory and transient overshooting is due to traders' memory of prior price controls. Prior human experiments show that overshooting disappears as human traders learn to ignore their memory of prior price controls that are no longer relevant.
} 
Finally, Panel 5 of Figure 4 (and Column 8 of Table 4) show that adding extramarginal traders (see Table 3 and Section 3.3 above) results in a higher modal peak and mean price.

\subsection{Price Path}

Figure 5 shows the transaction price paths averaged across all periods. The periods are identical because ZI traders do not learn. The mean price path for the no-price ceiling control in Panel 1 is horizontal at the CE price of 46.5. Panel 2 shows that the earlier transaction prices declined the most, but that the later transaction prices are barely affected. Panel 3 shows that resetting bids above the ceiling to the ceiling instead of rejecting them raises the number of bids at the ceiling and the average transaction price as compared to Panel 2. Panel 4 demonstrates that when each trader has only one unit (see Table 2), the transaction prices are somewhat higher than in Panel 2. Panel 5 shows that extramarginal traders have little additional effect.

\subsection{Price Dispersion}

The median (dark square) and interquartile range (vertical line) shown in Figure 6 highlight three phenomena: (1) the price dispersion declines from early to later transactions in a period with or without ceilings; (2) the ceiling lowers most transaction prices in the first half of the period; (3) the prices are skewed away from the ceiling.

\subsection{Allocative Efficiency}

Columns 1, 2, and 3 of the lower part of Table 4 show that non-binding price ceilings barely affect the high allocative efficiency of ZI markets. The efficiency declines when each trader has only one unit but the aggregate demand and supply is kept unchanged by adding more traders (Table 4 , Column 5). Adding extramarginal traders lowers efficiency further. In both cases, the ceiling lowers the allocative efficiency by one or two percent if bids and asks above the ceiling are rejected. There 
is no decline in efficiency, however, if bids above the ceiling are reset to the ceiling. Section 5 explores this further. Overall, there is weak evidence that effects of ceilings are harder to detect when traders have multiple units but can trade only one unit at a time.

\subsection{Buyers' and Sellers' Profits}

The bottom rows of Table 4 confirm that, by depressing prices, ceilings raise buyers' profits relative to sellers. The magnitude of the shift is highest in Smith and Williams'(1981) setting where traders have multiple units to trade, and lowest when each trader can trade only one unit in a period and there are additional extramarginal units. The magnitude of the shift decreases when bids above the ceiling are reset to the ceiling instead of being rejected.

The above simulation results for markets populated by ZI traders replicate many of the important consequences of imposing price controls on double auctions. These results, along with some prior work (Gode and Sunder, 1993b and 1997), suggest that the ZI model, with its minimalist approach to rationality, is a useful tool to study markets.

\section{Zl Traders: A Tool to Study Statistical Properties of Market Interactions}

To enhance our understanding of price controls we now explain the simulation results of the preceding section by using statistical analysis. This is possible because of the non-strategic nature of ZI traders. We discuss only the structural effects of market rules, assuming that traders do not respond to changes in market rules.

Imposing a ceiling above the equilibrium price after the market has settled to equilibrium should not affect market outcomes, but a ceiling imposed during the convergence process does affect market

outcomes. Simple changes in rules alter the convergence process. We identify three components of these effects: (1) exclusion of transaction prices above the ceiling; (2) higher likelihood of entry of 
extramarginal buyers because there is a lower chance that they will be outbid by intramarginal bidders; (3) the exclusion of extramarginal sellers whose costs exceed the ceiling. The first component is easy to see; our analysis highlights the other two.

The first effect of price ceilings is to rule out transactions above the specified limit. As shown in Cases 1 and 2 that follow, this lowers the mean transaction price, causes the transaction price path to slope upward toward the equilibrium price, and skews the distribution of transaction prices away from the equilibrium price. The exclusion effect partially explains the effect of price ceilings on transaction prices, but says nothing about the effect of price limits on trading volume and allocative efficiency. These consequences are discussed in Cases 3a, 3b, and 3c.

\subsection{Case 1: Effect on price level and relative profits of buyers and sellers}

Suppose there is just one seller with a cost of 0 and one buyer with a value of 1 as shown in Figure $7 \mathrm{~A} .{ }^{8}$ The ZI bids and asks are uniformly distributed from 0 to 1 . With no price ceiling the expected transaction price is 0.5 .

If a price ceiling is imposed at $\mathrm{c}(0<\mathrm{c}<1)$ and bids and asks above the ceiling are rejected by the market (reject mode), the expected transaction price is $\mathrm{c} / 2$, which is less than 0.5 , the mean price with no ceiling. Because proportion (1-c) of all bids/asks submitted are rejected, the expected number of rounds of bids/asks for a transaction increases by a factor of $1 / \mathrm{c}$.

Alternatively, if bids above the ceiling are reset to $\mathrm{c}$ (reset mode), the transactions that might have occurred between $\mathrm{c}$ and 1 will now occur at $\mathrm{c}$, lowering the mean price. The mean price is higher than that in the reject mode in which the transactions between $\mathrm{c}$ and 1 are redistributed over the range 0 to $\mathrm{c}$ instead of being concentrated at c. Thus, both implementations of ceilings (reject and

\footnotetext{
${ }^{8}$ We assume throughout that each trader has only one unit to trade each period. Non-binding price ceilings exclude extramarginal sellers whose costs equal or exceed the ceiling are excluded from the market. We start by assuming that all extramarginal sellers are excluded, and relax this assumption later.
} 
reset modes), lower the mean transaction price and shift profits from sellers to buyers. The simulation results for more complex demand and supply environments presented in Section 4 correspond well with these results.

The structural model predicts the "buffer" effect without assumptions about learning behavior and cognitive processes. The ZI model, however, says nothing about the "overreaction" to the removal of ceilings. Modeling such overreaction requires a more sophisticated model of trader behavior that incorporates learning and memory.

\subsection{Case 2: Price Slope and Variance}

To explore the effect of price ceiling on the slope of transaction price path, we now use the demand and supply functions shown in Figure 7B that allow two trades.

With no price ceiling, there will be two transactions, each with an expected price of 0.5 . Suppose all bids and asks above a ceiling of 0.5 are rejected (reject mode). The seller with the cost of 0 is more likely to trade first because his ask is lower on average. Because the bids above the ceiling are rejected, a valid bid is more likely ( 10 to 7 odds) to come from the buyer at 0.7 than from the buyer at 1 . Thus, the buyer at value 0.7 is more likely to trade earlier than the buyer at 1 , and this trade will occur at a price in the range $(0,0.5)$. The second transaction is more likely to occur between the seller at cost 0.3 and the buyer at value 1 . The feasible range for such a transaction is $(0.3,0.5)$ and therefore the mean price of the second transaction will be higher than the first transaction, i.e., the transaction prices will be upward sloping.

Resetting bids above the ceiling to the ceiling (reset mode) will raise the mean value of bids and transaction prices. Resetting also lowers the transaction price slope relative to the reject mode. When bids above the ceiling are reset to the ceiling, the seller at 0 is still likely to trade earlier than the 
seller at 0.3 , but the buyer at 1 is likely to trade earlier than the buyer at 0.7 because the buyer at 1 is likely to have a bid at the ceiling earlier than buyer at value 0.7 . This switch in the order in which buyers trade will increase the first transaction price and lower the second transaction price relative to the case where the bids above the ceiling were rejected. Because the low cost seller still trades earlier, the slope of the transaction price remains positive albeit less steep. Because lower cost units are traded early over a larger range of prices, the earlier transaction prices have a greater variance than the later prices. The simulation results in Section 4 for more complex demand and supply conditions are consistent with this analysis.

\subsection{Case 3: Effect of extramarginal traders on allocative efficiency and trading volume}

We now study the two subtle effects of price controls that deal with the role of extramarginal traders in the convergence process. This role is absent in the Walrasian tatonnement, but is present in all markets with sequential trading. Extramarginal trades lower efficiency because extramarginal buyers value the good less, and extramarginal sellers' costs are higher. Extramarginal trades increase the trading volume because a trade between the intramarginal sellers and the extramarginal buyers eventually leads to a trade between extramarginal sellers and intramarginal buyers, and vice versa.

Price ceilings lower efficiency by lowering the probability that intramarginal buyers will outbid extramarginal buyers, which increases the chances that extramarginal buyers will trade. Price ceilings raise efficiency, especially in the early part of trading, by excluding extramarginal sellers whose costs exceed the ceiling. However, if an extramarginal buyer does displace an intramarginal buyer in early trading, the only way the displaced intramarginal buyer can get back into the market is by trading with one of the extramarginal sellers. By excluding the high cost extramarginal sellers from trading, price ceilings preclude such trades, and thus lower allocative efficiency. We cannot 
establish whether the sum of these two opposite effects on efficiency is necessarily positive or negative.

Let us consider the demand and supply shown in Figure 7C. The CE price range is $(\beta,(1-\alpha))$ and the CE quantity is 1 . Because ZI traders leave no money on the table, the only cause of inefficiency is the entry of extramarginal traders. Gode and Sunder (1993b) and (1997) derive the allocative efficiency of similar markets without price controls.

\section{Case 3a: Price ceiling boosts efficiency by excluding extra-marginal sellers}

This case shows how a price ceiling can raise efficiency by keeping out the extramarginal sellers. Consider the above demand and supply when there are no extramarginal buyers $(\alpha>0$ and $\beta=0$ ). The only source of inefficiency is the trade between the extramarginal seller and the intramarginal buyer.

1. $c<(1-\alpha)$ : The ceiling locks out the extramarginal seller. $(\beta=0$ means that the extramarginal buyer is effectively absent.) Thus, the efficiency is 100 percent. This effect exists whether the bids above the ceiling are rejected or reset to the ceiling.

2. $\quad c>(1-\alpha)$ : Instead of locking out the extramarginal seller entirely, price ceilings in this case restrict the range of transaction prices for which entry of extramarginal seller is feasible. The restriction of feasible transaction prices is more effective if bids above the ceiling are rejected rather than reset to the ceiling.

Overall, price ceilings can raise efficiency by lowering the chances of extramarginal sellers entering the market.

These predictions are confirmed in Figure 8, which presents the average efficiency (on the xaxis) from 500 simulations of a market with $\alpha=0.4$, as a function of price ceiling (on the y-axis). 
The ceiling of 1 is effectively the no-ceiling benchmark with an efficiency of approximately 91 percent. Efficiency then rises asymptotically toward 100 percent as the ceiling is lowered toward $(1-\alpha)=0.6$. As compared to the reset mode, the efficiency is higher when the bids and asks above the ceiling are rejected because this raises the chances of extramarginal asks being excluded.

\section{Case 3b: Price ceiling lowers efficiency by reducing the ability of intramarginal buyers to outbid extramarginal buyers}

This case shows how price ceilings lower efficiency. They weaken the price priority rule by diminishing the range over which the intramarginal bidders can outbid the extramarginal bidders. Consider the above demand and supply with no extramarginal sellers $(\alpha=0$ and $\beta>0)$.

1. $\mathrm{c}<\beta$ : Competitive equilibrium theory predicts no efficiency loss. Isaac and Plott (1981) show, and the ZI model predicts, a higher efficiency loss. If bids above the ceiling are rejected, the intramarginal bid has a higher chance of being rejected than the extramarginal bid, raising the probability that extramarginal buyer will enter the market and lower efficiency. If bids above the ceiling are reset to the ceiling, then, as explained below, the probability of entry by the extramarginal buyer diminishes as compared to the no ceiling case. Suppose an extramarginal bid matches or exceeds the ceiling followed by an intramarginal bid that matches or exceeds the ceiling. With no ceiling, the intramarginal bid would supersede the extramarginal bid. If bids are reset to the ceiling, the intramarginal bid will be rejected because it came later and the extramarginal bid already equals the maximum allowable bid. This setting shows that a binding price ceiling lowers the efficiency more than that predicted by the competitive equilibrium theory because it lowers the probability that the intramarginal buyers will outbid the extramarginal buyers. 
2. $\quad c>\beta$ : If bids above the ceiling are rejected, and if the ceiling is relatively low, then the intramarginal buyer will still have a lower chance of submitting a valid bid as compared to the extramarginal buyer, raising the probability of entry by the extramarginal buyer and lowering efficiency. This effect would diminish as the ceiling is raised. If the bids above the ceiling are reset to the ceiling, then the ceiling will have no effect.

Average efficiencies obtained from 500 independent simulations of a market with $\beta=0.4$ are plotted on the $\mathrm{x}$-axis of Figure 8 against price ceilings (on the y-axis). In the reject mode, as the price ceiling is lowered from 1 to $\beta=0.4$, average efficiency drops sharply from about 91 percent to about 55.5 percent. A further drop in the ceiling below $\beta=0.4$ has no effect on efficiency. Conversely, in the reset mode, as the price ceiling is lowered from 1 to $\beta=0.4$, the average efficiency remains unchanged at about 91 percent. An additional drop in the ceiling below $\beta=0.4$ has the effect of reducing the efficiency gradually.

One can derive the allocative efficiency in the limiting cases as follows. Suppose the bids and asks above the ceiling are rejected. If the trade is concluded in the first round, the probability of a valid bid from the intramarginal bidder is $\mathrm{c}$, while the probability of a valid bid from the extramarginal bidder is $\mathrm{c} / 0.4$. Thus, the relative probabilities are $1 / 1.4$ and $0.4 / 1.4$, which gives an expected efficiency of $100 * 1 / 1.4+40 * 0.4 / 1.4=57$ percent which is what appears in Figure 8 . Suppose the bids above the ceiling are reset to the ceiling. If the ceiling is really low, both bidders have an equal chance of being at the ceiling and the average efficiency is $(1+0.4) / 2=70$ percent, the limiting case shown in the figure.

The above discussion points out two effects of ceilings. First, if bids above the ceiling are rejected, then the intramarginal buyers have a lower chance of submitting a valid bid (the frequency 
effect), thereby increasing the chance of extramarginal trades. This effect is absent if bids above the ceiling are reset to the ceiling. Second, a ceiling truncates the range over which intramarginal buyers can outbid extramarginal buyers (the truncation effect). This effect is present even if bids exceeding the ceiling are reset to the ceiling.

\section{Case 3c: Price ceilings lower efficiency by inhibiting efficiency recovering trades with extramarginal sellers}

Case $3 \mathrm{a}$ shows that ceilings can raise efficiency by lowering the chances of initial entry of extramarginal sellers. This case shows that the exclusion of extramarginal sellers can also lower efficiency if they are unavailable to trade with intramarginal buyers who were initially displaced by extramarginal buyers. Consider the above demand and supply when $\alpha>0$ and $\beta>0(1-\alpha>\beta)$

The presence of extramarginal traders on both sides of the market has two opposing effects on efficiency. First, with no extramarginal sellers, an inefficient trade could only be due to the entry of extramarginal buyers. The addition of extramarginal sellers raises the probability of an inefficient trade because now the extramarginal sellers can also trigger it. Second, some of the efficiency loss due to an initial inefficient trade is recovered due to subsequent trade between the remaining intramarginal and extramarginal traders. With no extramarginal sellers, the efficiency loss due to initial trade between the extramarginal buyer and the intramarginal seller is $1-\beta$ because the intramarginal buyer is left out of the market. With the extramarginal seller, there will be a subsequent trade between the intramarginal buyer and the extramarginal seller, which recovers a surplus of $\alpha$ and reduces the efficiency loss from $1-\beta$ to $1-\beta-\alpha$.

Let us see how price ceilings affect the above two factors. 
1. $\quad c>1-\alpha$ : This does not preclude the efficiency-recovering trades with extramarginal sellers following initial efficiency-reducing trades with extramarginal buyers. (The effects discussed in Case 3a remain.)

2. $\quad c<\beta$ : The efficiency enhancing effect is that the ceiling precludes initial entry by extramarginal sellers. However, it also has efficiency lowering effects discussed in Case $3 \mathrm{~b}$ and because partial recovery of surplus lost due to initial entry of extramarginal buyers is no longer feasible.

3. $<\mathrm{c}<1-\alpha$ : The only difference now is that, as discussed in Case $3 b$, the influence of extramarginal buyers is weakened as compared to the above case.

These cases illustrate how the ZI analysis brings out the structural effects of price controls. The richness of the analysis of these markets with ZI traders contrasts with the difficulty of gametheoretic analysis of double auctions with strategic traders.

\section{Summary and Conclusions}

The consequences of intelligent, rational, or other individual behavior have been the focus of economics. In contrast, using a simple, minimally rational, random model for trader behavior allows us to explore the structural consequences instead. Exploration of institutions and their economic properties is an important part of social sciences (North, 1990). We use the ZI model of traders to understand the effect of non-binding price controls in double auctions.

The ZI model has three major advantages. First, it provides a useful benchmark to study the effects of market rules on outcomes. Because ZI traders do not modify their behavior in response to market rules, any changes in market outcomes with ZI traders can be attributed to changes in market rules, not individual behavior. Second, the ZI model shows that the predictions of market outcomes 
which assume fully rational behavior can be valid with human subjects of varying backgrounds if market rules determine the statistical properties of interactions among traders. Third, the simplicity of the ZI model makes the analysis of market rules tractable. Markets with a finite number of traders who act sequentially are difficult to analyze, even if one uses a naive model of traders who have a modicum of memory, let alone strategic traders. The analytical results of Section 5 are derivable only from the extreme simplicity of the ZI model; each addition of intelligence and strategic behavior to ZI traders will significantly diminish their analytical value. The analytical value of the model lies in the insights gained, not in the direct validity of its assumptions.

Conjectures that link market outcomes to traders' specific strategies are difficult to verify. Traders' strategies are not observable, and conjectures of traders' strategies often have insufficient detail to be translated into computer programs, which require a complete specification of behavior. With cheaper technology, computational methods have become an increasingly attractive tool for economics research (Leijonhufvud, 1993). Computational work has helped distinguish between the individual behavior and aggregate outcomes. ${ }^{9}$ The simplicity of the ZI traders helps us appreciate how even seemingly simple changes in rules can cause complex changes in markets.

The ZI model does well in predicting market outcomes with human traders who have experience with double auction rules, but have little information about the demand and supply conditions [Cason and Friedman (1996)], which is typically the case in the early stages of markets. As human traders learn about demand and supply, market outcomes may diverge from those predicted by the ZI model because ZI traders have no memory. ZI traders are not an attempt to model human behavior accurately; they are a simple tool for exploring the dynamics of double auctions and isolating the powerful effect of market institutions.

\footnotetext{
${ }^{9}$ See Duh and Sunder, 1986; Gode and Sunder, 1993, 1997; Jamal and Sunder, 1996; Bosch and Sunder, 1994; Hardle and Kirman, 1995; Evans, 1997; Luo, 1995; and Cason and Friedman, 1996, 1997.
} 
We qualitatively replicate five of the seven important aspects of earlier experimental results (Isaac and Plott 1981, Smith and Williams 1981) on the effect of non-binding price limits when competitive equilibrium theory predicts no such effects. These effects are usually attributed to modification of human traders' strategies in response to price limits. The persistence of these effects with ZI traders who ignore market rules suggests that the cause is not necessarily a change in traders' behavior per se. In fact, these effects arise because human traders do not modify their behavior sufficiently to counter the effect of changes in market rules. The evidence that non-binding price ceilings have no effect if they are imposed after the market has settled to the equilibrium supports our hypothesis. Once traders have learned about the underlying market conditions, they are able to change their behavior to exactly offset the effect of changes in market rules. However, an analysis of the effect of price limits on convergence to equilibrium is important because in the real world the demand and supply are constantly changing, and price limits are often imposed in response to crises.

The ZI model provides insights about the market, especially in its initial and poorly understood process of converging to equilibrium. It shows how market rules affect the dynamics of double auctions by modifying the opportunity set. It highlights the role of extramarginal traders which is ignored in most prior theoretical and experimental research, even though without them the primary role of markets - the allocation of goods from low-cost intramarginal sellers (intramarginal sellers) to buyers who value them the most (intramarginal buyers) - is largely irrelevant. Our analysis shows that one must pay attention to the extramarginal demand and supply in designing experiments.

Price ceilings reduce the range over which intramarginal buyers can outbid extramarginal buyers and exclude extramarginal sellers above the ceiling. The first effect unambiguously lowers allocative efficiency by reducing the probability that the intramarginal buyers will keep out extramarginal buyers by outbidding them. The second effect has a mixed impact. It can increase efficiency because 
the exclusion of extramarginal sellers above the ceiling reduces the probability of extramarginal sellers displacing intramarginal sellers. It can reduce efficiency because if the extramarginal buyers displace intramarginal buyers initially, the intramarginal buyers have no one to trade with. Our ZI simulations with market demand and supply used in prior human experiments indicate that nonbinding price ceilings increase efficiency overall.

Since the overshooting effect that dissipates with experience has already been documented in human experiments, it should be possible to generate such effects in simulations carried out with programmed traders more sophisticated than ZI. However, from the ZI simulations conducted so far, we cannot yet identify the aspects of additional intelligence that are critical to such overshooting. We do believe that the bubble phenomena which tend to arise from traders coordinating their expectations in incomplete markets for financial assets, monetary economies, etc., (e.g., Marimon, Spear and Sunder 1993 and Hirota and Sunder 2002) are unlikely to arise in the complete markets analyzed in the present paper.

Individuals do not act alone; "they stand on the scaffolding of larger scale constraining structures [that are] sometimes the strongest carrier of maximizing force" (Clark, 1997). Simon (1996) showed that significant consequences of substantive rationality can be replicated with simple procedural rationality. Mirowski (2002) and Sunder (2003) suggest that we may be well on our way to integrating complex and weak human rationality of cognitive sciences with the simplicity and power of exchange institutions in classical economics. 


\section{References}

Becker, Gary S. Irrational Behavior and Economic Theory. Journal of Political Economy 70 (1962): $1-13$.

Bosch, Antoni, and Shyam Sunder. Tracking the Invisible Hand: Convergence of Double Auctions to Competitive Equilibrium. Carnegie Mellon University Working Paper, Revised February 1999.

Cason, Timothy and Daniel Friedman. 1996. Dynamics of Double Auctions, Journal of Economic Dynamics and Control.

Cason, Timothy and Daniel Friedman. 1997. Price Formation in Single Call Markets. Econometrica 65:2 (March 1997), 311-3345.

Clark, Andy. 1997. Being There: Putting Brain, Body, and World Together Again. Cambridge: MIT Press.

Coursey, Don, and Vernon L. Smith. 1983. Price Controls in a Posted Offer Market. The American Economic Review 73:1 (March), 218-21.

Duh, Rong-Ruey and Shyam Sunder, Base Rate Fallacy: Incentives and Learning in a Market Environment, in Shane Moriarty, editor, Laboratory Market Studies, University of Oklahoma (1986), 50-79.

Easley, David, and John O. Ledyard. 1993. Theories of Price Formation and Exchange in Double Oral Auctions. In Daniel Friedman and John Rust, eds. The Double Auction Market: Institutions, Theories and Evidence, A proceedings volume in the Santa Fe Institute Studies in the Sciences of Complexity. Reading, MA: Addison Wesley.

Evans, Dorla A. 1997. The Role of Markets in Reducing Expected Utility Violations. Journal of Political Economy 105 (3), 622-636.

Friedman, Daniel. 1984. On the Efficiency of Double Auction Markets. American Economic Review $74,60-72$.

Gell-Mann, Murray, (1994). The Quark and the Jaguar: Adventures in the Simple and the Complex. New York: W. H. Freeman and Company.

Gode, Dhananjay K., and Shyam Sunder. (1993a). Allocative Efficiency of Markets with Zero Intelligence (ZI) Traders: Market as a Partial Substitute for Individual Rationality. Journal of Political Economy, 101, (1993): No.1., 119-137.

Gode, Dhananjay K. and Shyam Sunder, (1993b). Lower Bounds for Efficiency of Surplus Extraction in Double Auctions in D. Friedman and J. Rust, eds., The Double Auction Market, Santa Fe Institute Studies in Sciences of Complexity, Proceedings Volume XIV. New York: Addison-Wesley. 
Gode, Dhananjay K. and Shyam Sunder, (1997). What Makes Markets Allocationally Efficient? The Quarterly Journal of Economics 112 (2), 603-630.

Hardle, W. and A. Kirman. 1995. Neoclassical Demand: A Model-Free Examination of PriceQuantity Relations in the Marseilles Fish Market. Journal of Econometrics 67 (1), 227-257.

Hayek, Friederich A. 1945. The Uses of Knowledge in Society, The American Economic Review 35 (September), 519-30.

Hirota, Shinichi, and Shyam Sunder. 2002. Stock Market as a 'Beauty Contest': Investor Beliefs and Price Bubbles sans Dividend Anchors, Yale University Working Paper. http://papers.ssrn.com/sol3/papers.cfm?abstract id=302393.

Isaac, R. Mark, and Charles R. Plott, (1981). Price Controls and the Behavior of Auction Markets: An Experimental Evaluation. American Economic Review 71:3 (June), 448-459.

Jamal, Karim and Shyam Sunder, Bayesian Equilibrium in Double Auctions Populated by Biased Heuristic Traders, Journal of Economic Behavior and Organization Vol. 31 No. 2 (November 1996), 273-291.

Kagel, John H. 1995. Auctions: A Survey of Experimental Research. In J. H. Kagel and A. E. Roth, eds., The Handbook of Experimental Economics, 501-85. Princeton, NJ: Princeton University Press.

Leijonhufvud, A. 1993. Towards a Not-Too-Rational Macroeconomics. Southern Economic Journal $60(1), 1-13$.

Luo, G. Y. 1995. Evolution and Market Competition. Journal of Economic Theory 67 (1), 223-50.

Marimon, Ramon, Stephen A. Spear and Shyam Sunder. 1993. Expectationally-Driven Market Volatility: An Experimental Study, Journal of Economic Theory, Vol. 61, No. 1 (1993), 74103.

Mirowski, Philip. 2002. Machine Dreams: Economics Becomes a Cyborg Science. New York: Cambridge University Press.

North, Douglass C. 1990. Institutions, Institutional Change and Economic Performance. New York; Cambridge University Press.

Rust J., Miller, J.H., and Palmer, R (1993). Behavior of Trading Automata in a Computerized Double Auction Market. In The Double Auction Market: Institutions, Theories, and Evidence, edited by D. Friedman and J. Rust, Santa Fe Institute Series in the Sciences of the Complexity, Proceedings Volume XV. New York, NY, Addison-Wesley.

Scherer, F. M., Industrial Pricing: Theory and Evidence. Chicago: Rand McNally College Pub. Co. 1970. 
Simon, Herbert A. 1996. The Sciences of the Artificial. Third Edition. Cambridge, Mass.: MIT Press.

Smith, Vernon L. And Arlington W. Williams. 1981. On Nonbinding Price Controls in a Competitive Market. The American Economic Review 71: (June), 467-74.

Sunder, Shyam. 2003. Markets as Artifacts: Aggregate Efficiency from Zero-Intelligence Traders, Yale University Working Paper. http://papers.ssrn.com/sol3/papers.cfm?abstract id=309750.

Wilson, Robert. 1987. Equilibrium in Bid-Ask Markets. In Arrow and the Ascent of Economic Theory: Essays in Honor of Kenneth J. Arrow, edited by G. Feiwel. London: Macmillan. 


\section{Appendix: Double Auction Market Rules}

Double auctions can be run under a variety of rules. This section describes what we mean by the term "continuous double auction without replacement."

\section{Definitions}

Market, periods, transactions, and rounds constitute a nested hierarchy in time. A market is divided into periods, usually of fixed duration. There may be several transactions in a period. Each transaction consists of one or more rounds of solicitation of bids and asks from traders.

At the beginning of a period, all market variables are reset and traders get fresh endowments. Except traders' memory and wealth, all periods are identical. Because ZI traders lack memory and ignore wealth, all periods in ZI markets are statistically identical. Each period may have one or more transactions. When bidding starts at the beginning of a transaction, the current bid is reset to zero and the current ask is reset to $\mathrm{M}$ (an exogenous upper bound known to all traders).

Bids and asks are solicited in a series of rounds and submitted to a central clearinghouse. If a new bid exceeds the current bid, it becomes the current bid. Similarly, if the new ask is less than the current ask, it becomes the current ask. A trade occurs when the current bid equals or exceeds the current ask. (This is frequent in ZI markets, but rare in human markets.) The transaction price can be the current bid or ask depending on which was submitted earlier (or later), or a prespecified weighted average of the current bid and ask. If a round results in no transactions, more rounds follow until there is a transaction, or the period ends.

\section{Sequencing}

The unlikely event that two or more human traders act at the same time is resolved by random selection. When ZI traders replace human traders, all traders theoretically submit their bids and asks at the same time, so an orderly mechanism to solicit bids and asks and match them is necessary. 
In a synchronized double auction, both the solicitation of bids/asks as well as their matching within each round is simultaneous or batched. All traders are solicited for their bids and asks. While submitting a bid or ask, a trader does not know the bids and asks submitted by other traders in that round. The highest bid and the lowest ask from the round are then used to update the current bid and ask. If the current bid exceeds or equals the current ask, a transaction occurs, the current bid and ask are reset, and the first round of bids and asks for the next transaction are solicited. If the current bid is less than the current ask, they are carried over to the next round of bids and asks for the same transaction. Because the bids and asks of all traders in a given round are considered all at once, the order in which they are solicited is irrelevant. Because only the highest of all bids and the lowest of all asks are submitted in a given round matter, the order in which they are picked for comparison is irrelevant.

In a continuous double auction, a trader is randomly solicited and his bid/ask is used to update the current bid/current ask. In solicitation without replacement, the next trader is randomly picked from unpicked traders in a round. The process continues until the current bid exceeds or equals the current ask. If all traders have been picked, the next round of random order solicitation of bids/asks for the transaction starts. Solicitation without replacement ensures that every trader has a chance to submit a proposal before someone has the chance to submit a second proposal. In solicitation with replacement, the next trader is randomly picked from all traders. Such sampling allows a trader to be solicited many times before others are solicited, and all rounds of a transaction merge into a continuum until the transaction is completed.

In a semi-continuous or hybrid auction, the batched bid/ask solicitation feature of a synchronized double auction is combined with the sequential matching feature of continuous double auction. Similar to a synchronous auction, first all bids/asks are gathered at the clearinghouse. Then 
they are randomly selected without replacement to update the current bid/current ask. If the current bid at any stage matches or exceeds the current ask, a transaction is completed, the remaining bids/asks are discarded, and the auction moves to the next transaction; if no match occurs, the auction moves to the next round.

In summary, bids and asks are solicited from traders and matched in a sequence of rounds. One or more rounds may be needed for a transaction, and all transactions until endowments are reset constitute a period. A market may consist of one or more periods. Depending on the sequencing of solicitation and matching of bids and asks, we can carry out a synchronized, continuous (with or without replacement) and hybrid double auction.

We picked the continuous double auctions without replacement in which the transaction occurs at the earlier of the current bid and ask because, in our opinion, this mechanism mimics laboratory auctions. Because our ZI traders ignore the current bid and ask, the results would be the same with a semi-continuous auction. 
Table 1*: Unit Values and Costs

\begin{tabular}{|c|c|c|c|c|c|c|c|}
\hline & \multicolumn{6}{|c|}{ Unit } & \multirow{2}{*}{$\begin{array}{c}\text { Theoretical } \\
\text { Profit** }\end{array}$} \\
\hline Trader & 1 & 2 & 3 & 4 & 5 & 6 & \\
\hline Buyer 1 & 53.5 & 51.0 & 47.0 & 46.0 & 45.0 & - & 12.0 \\
\hline Buyer 2 & 56.0 & 49 & 48.0 & 46.5 & 45.5 & - & 13.5 \\
\hline Buyer 3 & 56.0 & 49.0 & 48.0 & 46.5 & 46.0 & 45.0 & 13.5 \\
\hline Buyer 4 & 53.5 & 51.0 & 47.0 & 46.5 & 45.5 & - & 12.0 \\
\hline Seller 5 & 39.5 & 42.0 & 46.0 & 46.5 & 47.5 & - & 12.0 \\
\hline Seller 6 & 37.0 & 44.0 & 45.0 & 46.5 & 47.5 & - & 13.5 \\
\hline Seller 7 & 39.5 & 42.0 & 46.0 & 47.0 & 48.0 & - & 12.0 \\
\hline Seller 8 & 37.0 & 44.0 & 45.0 & 46.5 & 47.0 & 48.0 & 13.5 \\
\hline
\end{tabular}

*Reproduced from Table 1 from Smith and Williams (1981) after scaling all values and costs by a factor of 10 .

** Profit if the units were traded at the competitive equilibrium price

Competitive equilibrium price $=46.5$, quantity $=12$ to 15

Maximum extractable surplus (or maximum total profit of all traders) $=102$

Surplus extracted (or total profit of all traders) if all units are traded $=90$ 
Table 2*: Unit Values and Costs

\begin{tabular}{|c|c|c|c|c|c|}
\hline Buyers & Value & $\begin{array}{c}\text { Theoretical } \\
\text { Profit** }\end{array}$ & Sellers & Cost & $\begin{array}{c}\text { Theoretical } \\
\text { Profit** }\end{array}$ \\
\hline Buyer 1 & 56.0 & 9.5 & Seller 22 & 37.0 & 9.5 \\
\hline Buyer 2 & 56.0 & 9.5 & Seller 23 & 37.0 & 9.5 \\
\hline Buyer 3 & 53.5 & 7.0 & Seller 24 & 39.5 & 7.0 \\
\hline Buyer 4 & 53.5 & 7.0 & Seller 25 & 39.5 & 7.0 \\
\hline Buyer 5 & 51.0 & 4.5 & Seller 26 & 42.0 & 4.5 \\
\hline Buyer 6 & 51.0 & 4.5 & Seller 27 & 42.0 & 4.5 \\
\hline Buyer 7 & 49.0 & 2.5 & Seller 28 & 44.0 & 2.5 \\
\hline Buyer 8 & 49.0 & 2.5 & Seller 29 & 44.0 & 2.5 \\
\hline Buyer 9 & 48.0 & 1.5 & Seller 30 & 45.0 & 1.5 \\
\hline Buyer 10 & 48.0 & 1.5 & Seller 31 & 45.0 & 1.5 \\
\hline Buyer 11 & 47.0 & 0.5 & Seller 32 & 46.0 & 0.5 \\
\hline Buyer 12 & 47.0 & 0.5 & Seller 33 & 46.0 & 0.5 \\
\hline Buyer 13 & 46.5 & 0 & Seller 34 & 46.5 & 0 \\
\hline Buyer 14 & 46.5 & 0 & Seller 35 & 46.5 & 0 \\
\hline Buyer 15 & 46.5 & 0 & Seller 36 & 46.5 & 0 \\
\hline Buyer 16 & 46.0 & 0 & Seller 37 & 47.0 & 0 \\
\hline Buyer 17 & 46.0 & 0 & Seller 38 & 47.0 & 0 \\
\hline Buyer 18 & 45.5 & 0 & Seller 39 & 47.5 & 0 \\
\hline Buyer 19 & 45.5 & 0 & Seller 40 & 47.5 & 0 \\
\hline Buyer 20 & 45.0 & 0 & Seller 41 & 48.0 & 0 \\
\hline Buyer 21 & 45.0 & 0 & Seller 42 & 48.0 & 0 \\
\hline
\end{tabular}

${ }^{*}$ Transformation of Table 1 by assigning a single unit to each buyer and seller;

** Profit if the units were traded at the competitive equilibrium price

Competitive equilibrium price $=46.5$, quantity $=12$ to 15

Maximum extractable surplus (or maximum total profit of all traders) $=102$

Surplus extracted (or total profit of all traders) if all units are traded $=90$ 
Table 3*: Unit Values and Costs

\begin{tabular}{|c|c|c|c|c|c|}
\hline Buyers & Value & $\begin{array}{c}\text { Theoretical } \\
\text { Profit** }\end{array}$ & Sellers & Cost & $\begin{array}{c}\text { Theoretical } \\
\text { Profit** }\end{array}$ \\
\hline Buyer 1 & 56.0 & 9.5 & Seller 22 & 37.0 & 9.5 \\
\hline Buyer 2 & 56.0 & 9.5 & Seller 23 & 37.0 & 9.5 \\
\hline Buyer 3 & 53.5 & 7.0 & Seller 24 & 39.5 & 7.0 \\
\hline Buyer 4 & 53.5 & 7.0 & Seller 25 & 39.5 & 7.0 \\
\hline Buyer 5 & 51.0 & 4.5 & Seller 26 & 42.0 & 4.5 \\
\hline Buyer 6 & 51.0 & 4.5 & Seller 27 & 42.0 & 4.5 \\
\hline Buyer 7 & 49.0 & 2.5 & Seller 28 & 44.0 & 2.5 \\
\hline Buyer 8 & 49.0 & 2.5 & Seller 29 & 44.0 & 2.5 \\
\hline Buyer 9 & 48.0 & 1.5 & Seller 30 & 45.0 & 1.5 \\
\hline Buyer 10 & 48.0 & 1.5 & Seller 31 & 45.0 & 1.5 \\
\hline Buyer 11 & 47.0 & 0.5 & Seller 32 & 46.0 & 0.5 \\
\hline Buyer 12 & 47.0 & 0.5 & Seller 33 & 46.0 & 0.5 \\
\hline Buyer 13 & 46.5 & 0 & Seller 34 & 46.5 & 0 \\
\hline Buyer 14 & 46.5 & 0 & Seller 35 & 46.5 & 0 \\
\hline Buyer 15 & 46.5 & 0 & Seller 36 & 46.5 & 0 \\
\hline Buyer 16 & 46.0 & 0 & Seller 37 & 47.0 & 0 \\
\hline Buyer 17 & 46.0 & 0 & Seller 38 & 47.0 & 0 \\
\hline Buyer 18 & 45.5 & 0 & Seller 39 & 47.5 & 0 \\
\hline Buyer 19 & 45.5 & 0 & Seller 40 & 47.5 & 0 \\
\hline Buyer 20 & 45.0 & 0 & Seller 41 & 48.0 & 0 \\
\hline Buyer 21 & 45.0 & 0 & Seller 42 & 48.0 & 0 \\
\hline Buyer 21A & 44.0 & 0 & Seller 42A & 49.0 & 0 \\
\hline Buyer 21B & 44.0 & 0 & Seller 42B & 49.0 & 0 \\
\hline Buyer 21C & 42.0 & 0 & Seller 42C & 51.0 & 0 \\
\hline Buyer 21D & 39.5 & 0 & Seller 42D & 53.5 & 0 \\
\hline & & & & \\
\hline
\end{tabular}

*Transformation of Table 1 by assigning a single unit to each buyer and seller and addition of extramarginal units;

** Profit if the units were traded at the competitive equilibrium price

Competitive equilibrium price $=46.5$, quantity $=12$ to 15

Maximum extractable surplus (or maximum total profit of all traders) $=102$

Surplus extracted (or total profit of all traders) if all units are traded $=57$ 
Table 4: Summary Statistics (100 periods for each column)

\begin{tabular}{|c|c|c|c|c|c|c|c|c|c|}
\hline & \multicolumn{6}{|c|}{ Smith and Williams market demand and supply } & \multicolumn{3}{|c|}{$\begin{array}{c}\text { Extended demand and supply (more } \\
\text { extramarginal traders) } \\
\text { Single unit per trader (Table } 3 \text { ) } \\
\end{array}$} \\
\hline & \begin{tabular}{|c|}
$(1)$ \\
Panel 1 \\
No Ceiling \\
\end{tabular} & $\begin{array}{c}(2) \\
\text { Panel } 2 \\
\text { Ceiling }=47 \\
\text { Reject } \\
\text { invalid bids }\end{array}$ & \begin{tabular}{|c|}
$(3)$ \\
Panel 3 \\
Ceiling $=47$ \\
Reset \\
invalid bids
\end{tabular} & \begin{tabular}{|c|} 
(4) \\
No Ceiling \\
\end{tabular} & \begin{tabular}{|c|}
$(5)$ \\
Panel 4 \\
Ceiling $=47$ \\
Reject \\
invalid bids
\end{tabular} & $\begin{array}{c}(6) \\
\text { Ceiling }=47 \\
\text { Reset } \\
\text { invalid bids }\end{array}$ & \begin{tabular}{|c|} 
(7) \\
No Ceiling \\
\end{tabular} & \begin{tabular}{|c|}
$(8)$ \\
Panel 5 \\
Ceiling $=47$ \\
Reject \\
invalid bids
\end{tabular} & $\begin{array}{c}(9) \\
\text { Ceiling }=47 \\
\text { Reset } \\
\text { invalid bids }\end{array}$ \\
\hline Mean & 46.45 & 45.01 & 45.67 & 46.45 & 45.63 & 46.07 & 46.55 & 45.71 & 46.01 \\
\hline Median & 46.47 & 45.89 & 46.49 & 46.46 & 46.20 & 46.66 & 46.52 & 46.25 & 46.66 \\
\hline Std. Deviation & 2.75 & 2.09 & 1.98 & 2.30 & 1.56 & 1.43 & 2.35 & 1.45 & 1.59 \\
\hline Skewness & -0.02 & -1.49 & -2.01 & -0.15 & -2.17 & -2.44 & 0.03 & -2.18 & -2.43 \\
\hline Kurtosis & 1.55 & 1.51 & 3.70 & 2.35 & 5.49 & 7.15 & 2.26 & 5.68 & 6.50 \\
\hline \multicolumn{10}{|l|}{ Total } \\
\hline Mean & 99.90 & 99.88 & 99.97 & 98.14 & 96.24 & 99.46 & 97.36 & 96.29 & 99.08 \\
\hline Std. Error of Mean & 0.03 & 0.03 & 0.01 & 0.13 & 0.44 & 0.06 & 0.18 & 0.49 & 0.12 \\
\hline \multicolumn{10}{|l|}{ Buyers } \\
\hline Mean & 101.26 & 138.78 & 120.81 & 99.72 & 117.73 & 110.69 & 95.93 & 115.29 & 111.69 \\
\hline Std. Error of Mean & 1.64 & 1.07 & 1.08 & 1.32 & 1.26 & 1.01 & 1.31 & 1.15 & 0.94 \\
\hline \multicolumn{10}{|l|}{ Sellers } \\
\hline Mean & 98.55 & 60.99 & 79.13 & 96.56 & 74.74 & 88.23 & 98.78 & 77.29 & 86.48 \\
\hline Std. Error of Mean & 1.64 & 1.07 & 1.08 & 1.31 & 0.94 & 1.00 & 1.32 & 0.84 & 0.97 \\
\hline
\end{tabular}


Figure 1: Results from Laboratory Experiments with Human Subjects

(Figure 1. Experiment 2:26 from Smith and Williams, 1981)

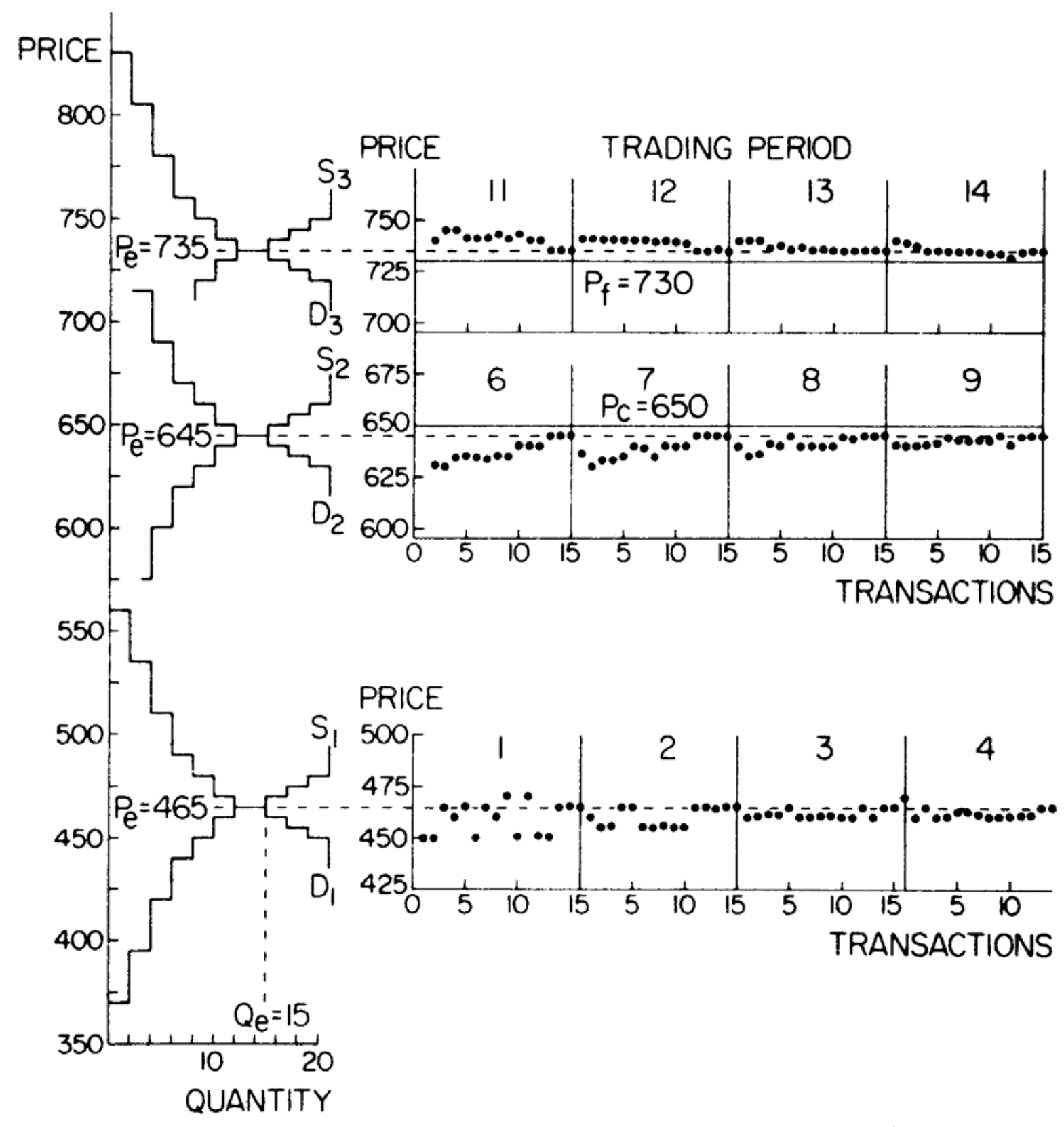

FIGURE 1. EXPERIMENT 2:26 
Figure 2: Results from Laboratory Experiments with Human Subjects

(Figure 3 from Smith and Williams, 1981)
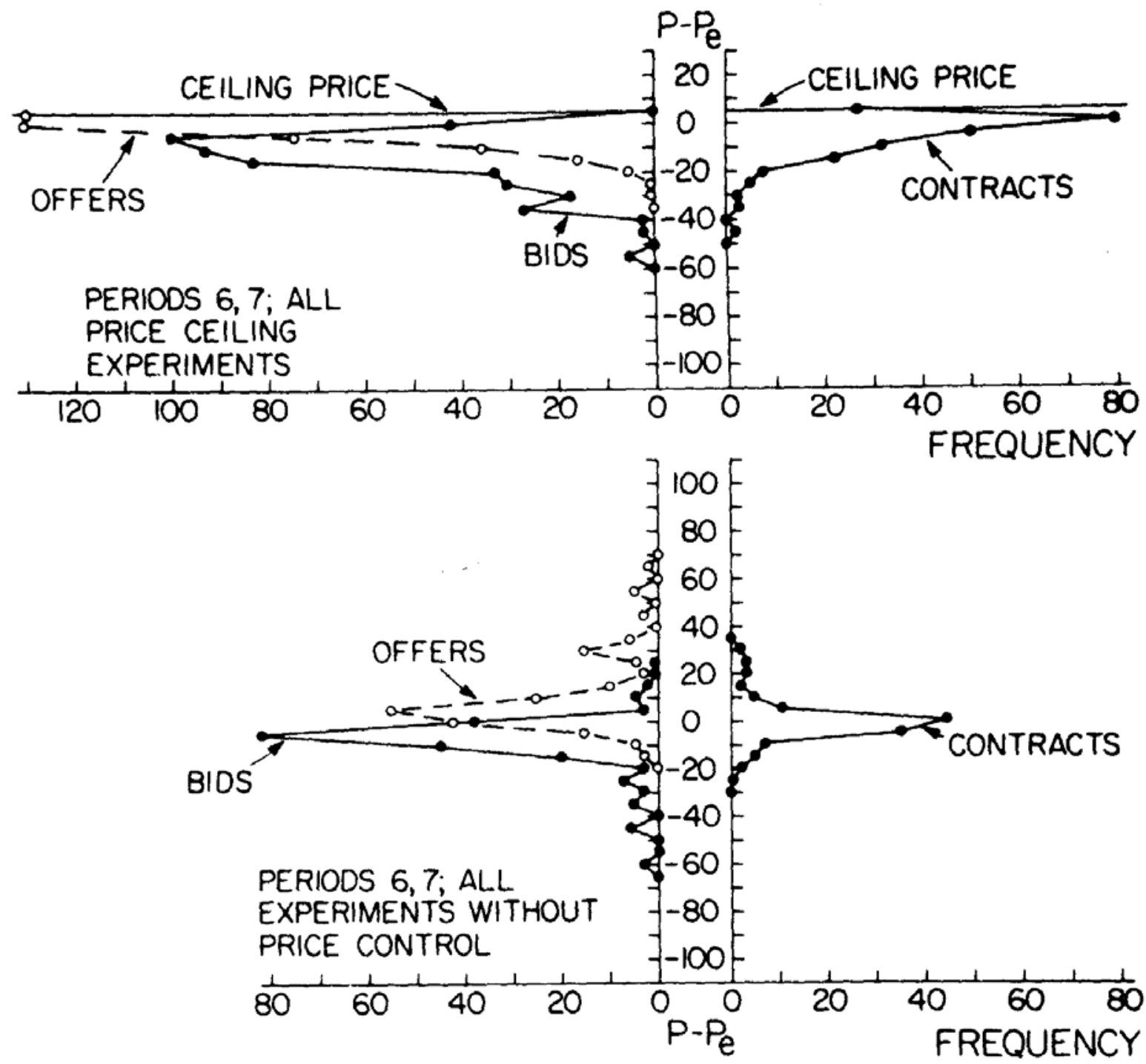

Figure 3. Price Ceiling Frequency Distributions 
Figure 3: Demand and Supply

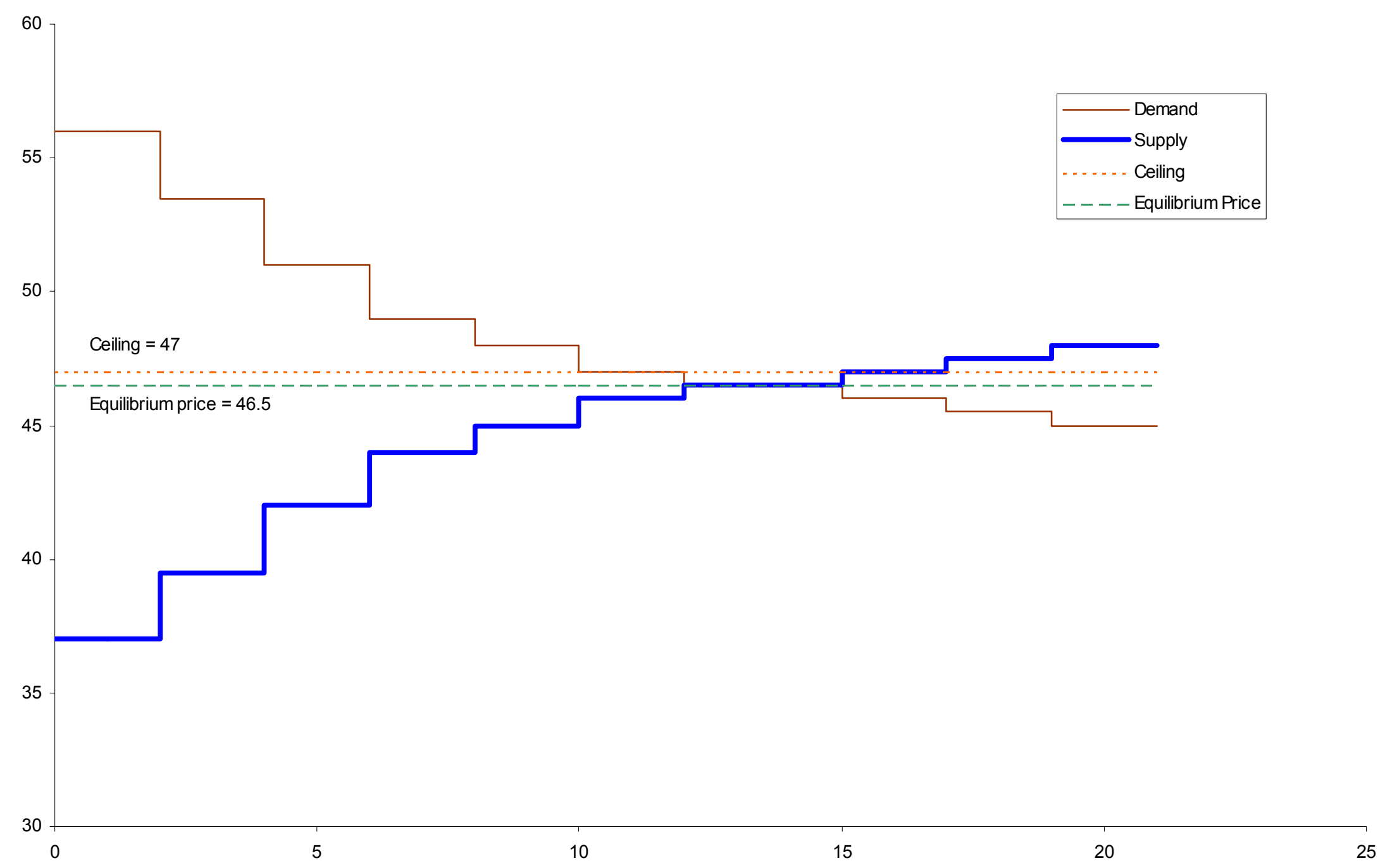


Figure 4: Histograms of Transaction Price Distributions

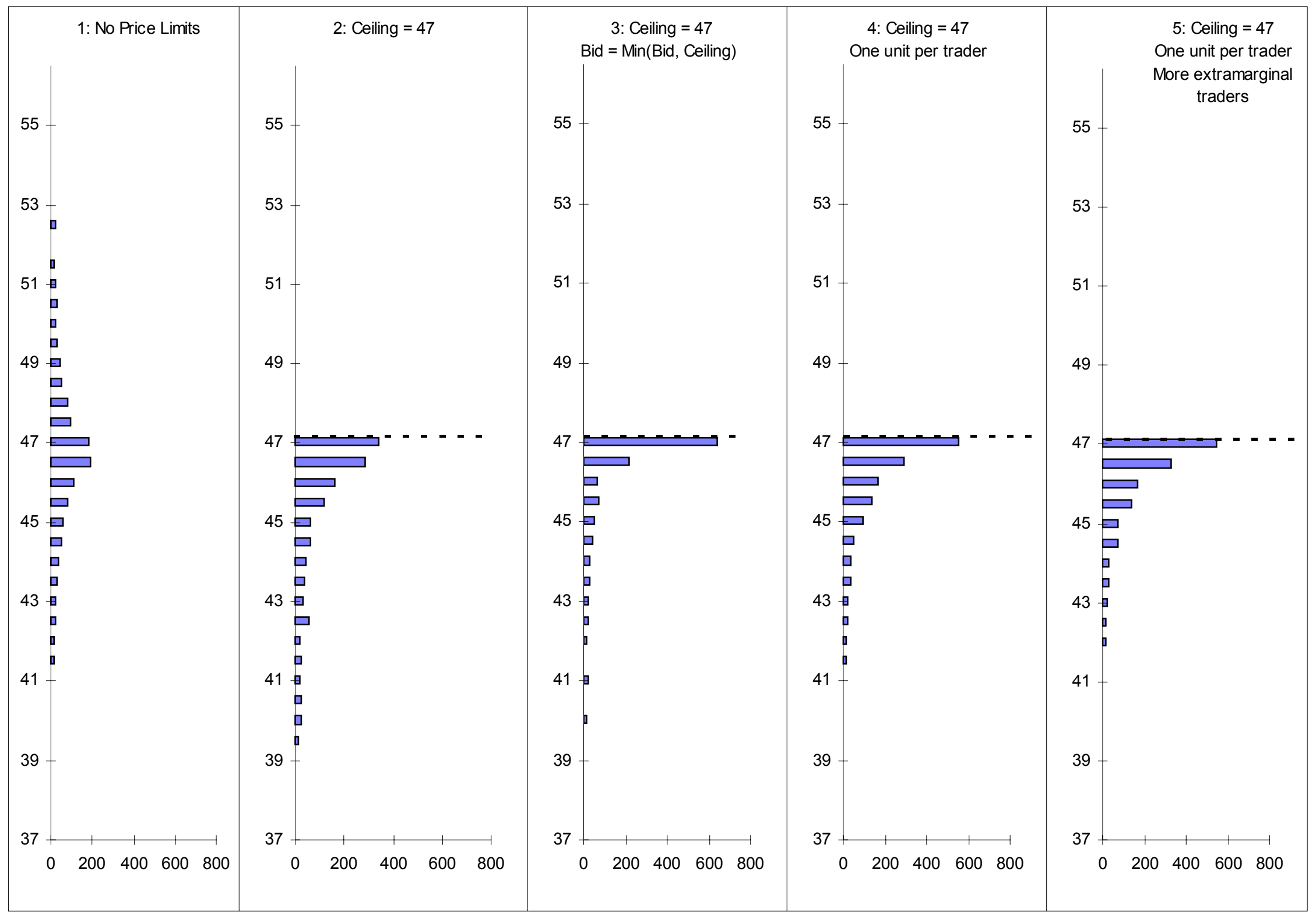


Figure 5: Intra-period Mean of Transaction Price Series

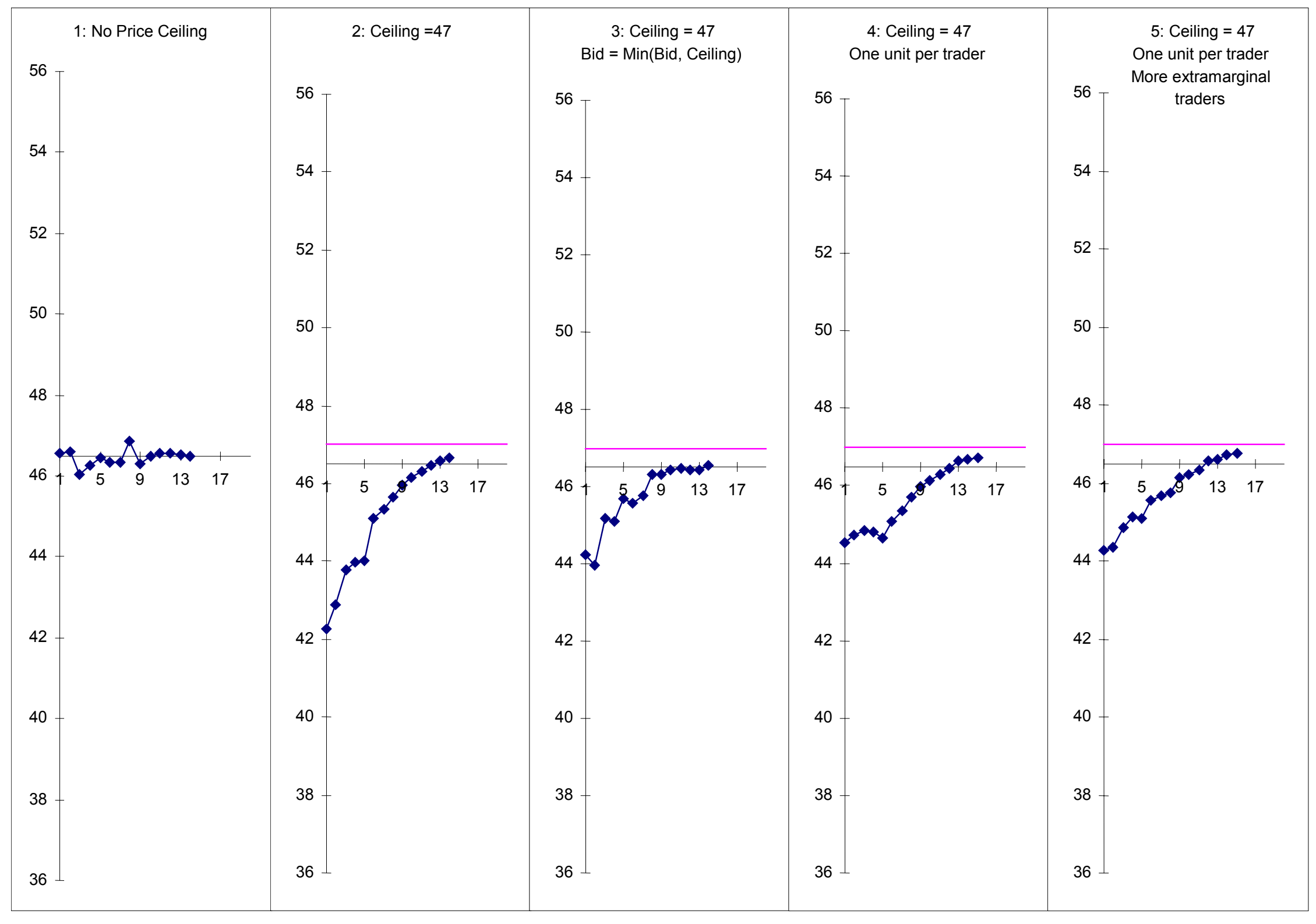


Figure 6:IntraPeriod Median and Inter-Quartile Range of Transaction Price Series

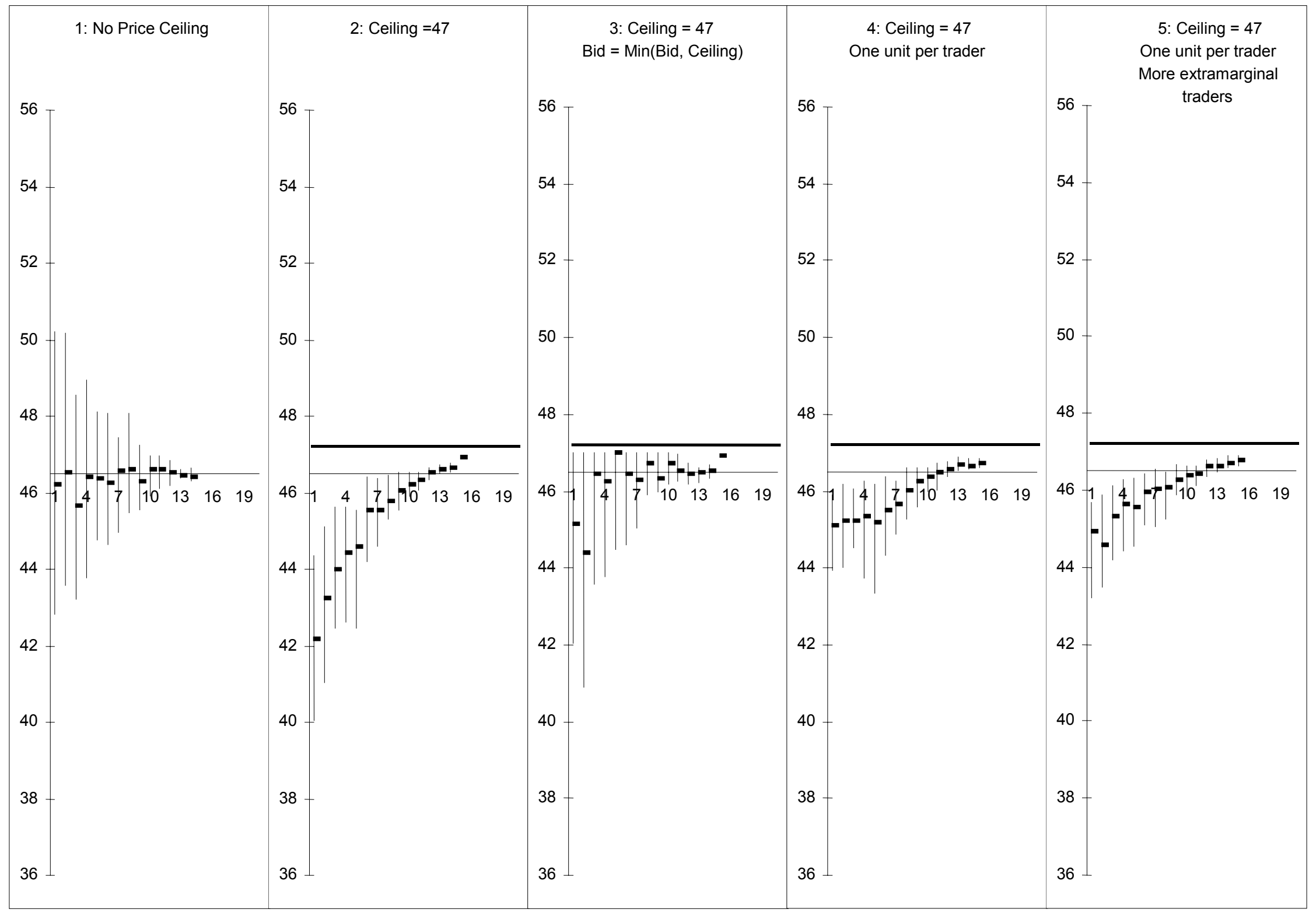


Figure 7: Demand, Supply and Price Controls
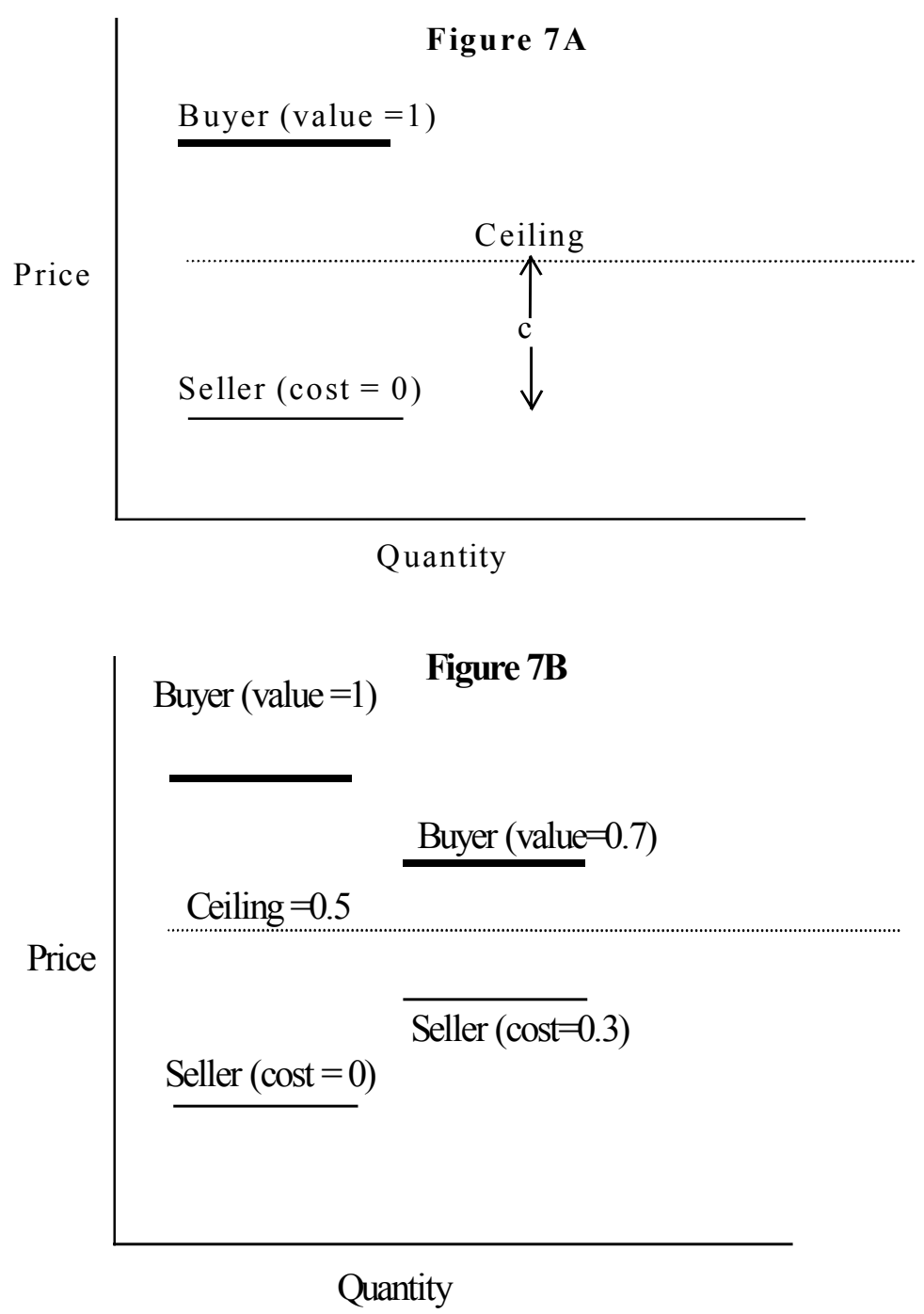

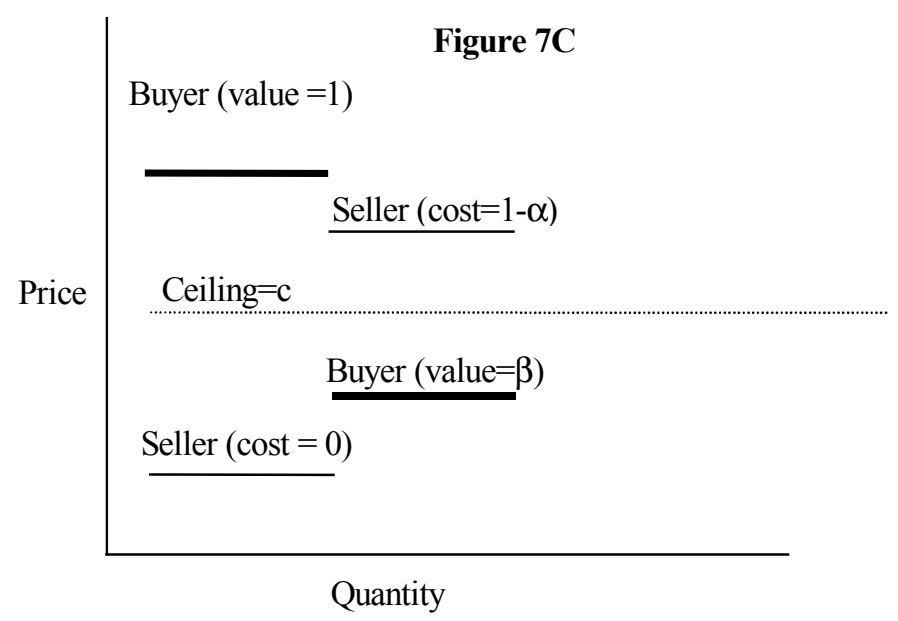




\section{Figure 8}

Demand and Supply Case 3a

(Extramarginal Seller at 0.6)

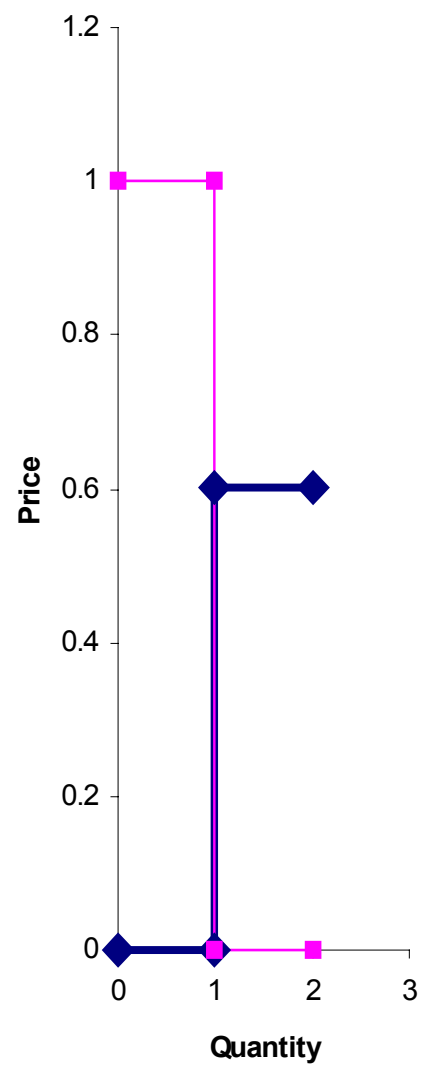

Effect of Price Ceiling on Allocative Efficiency

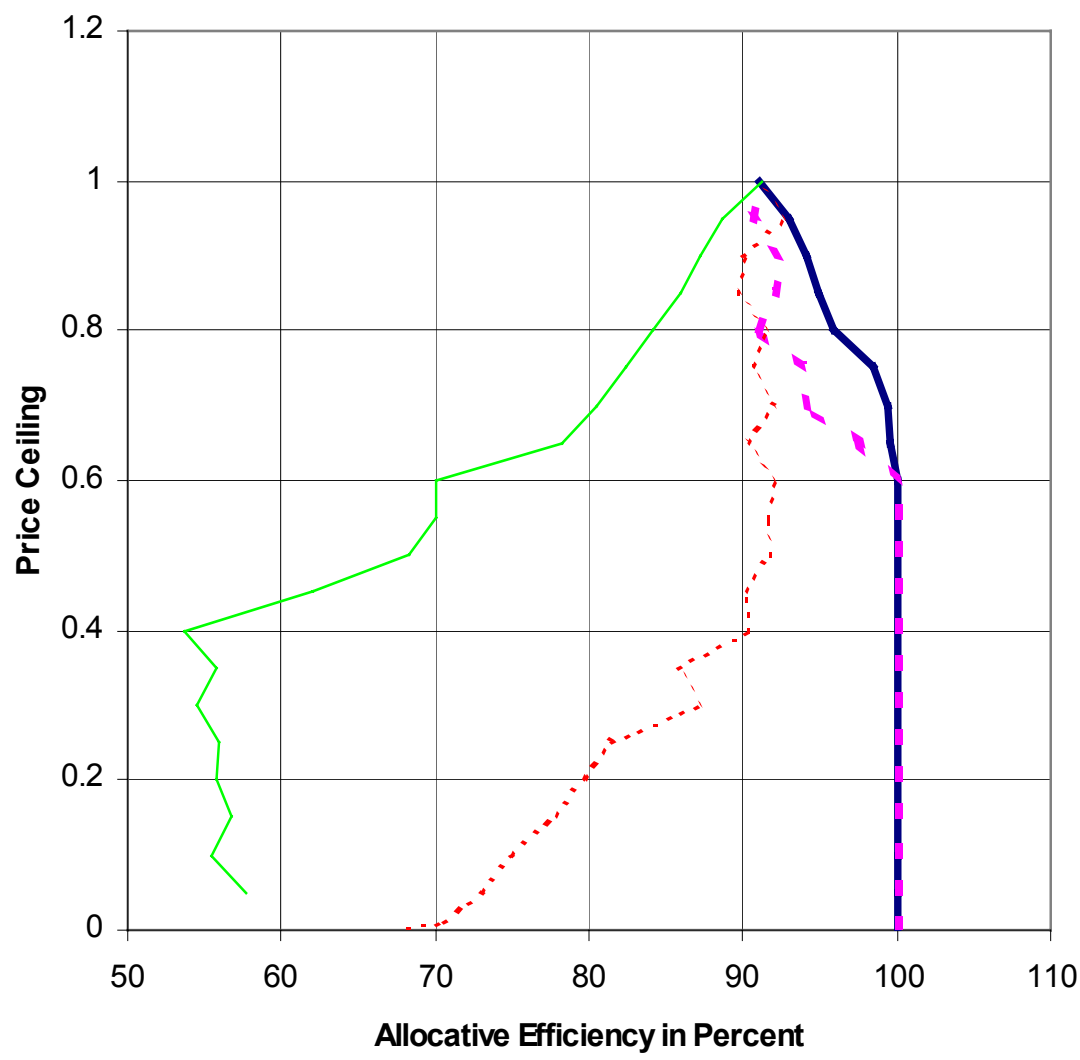

Demand and Supply Case 3b

(Extramarginal Buyer at 0.4)

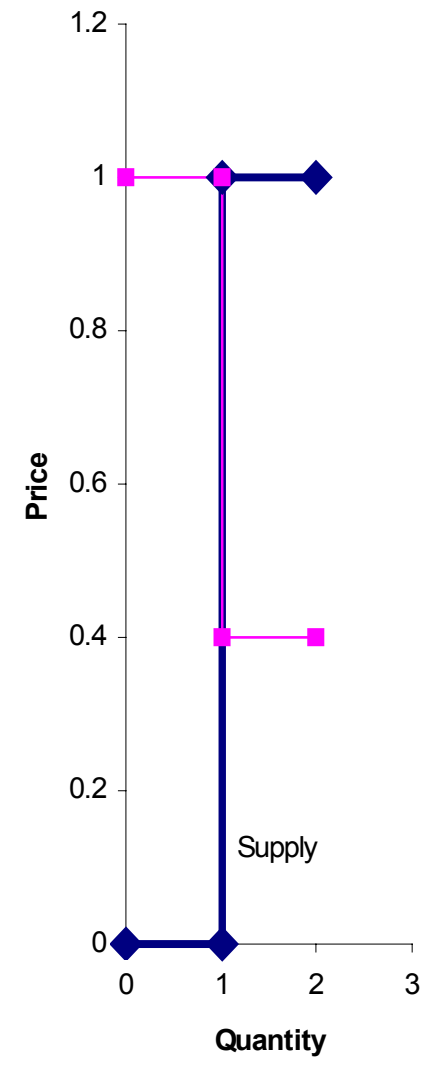

